\title{
Residual Stress Behavior in Hardened Shot Peened 42CrMo4 Specimens during Fatigue Load
}

\author{
David Cseh ${ }^{1, a^{*}}$, Valeria Mertinger ${ }^{1, \mathrm{~b}}$ and Janos Lukacs ${ }^{2, \mathrm{c}}$ \\ ${ }^{1}$ Institute of Physical Metallurgy, Metalforming and Nanotechnology, University of Miskolc, $\mathrm{H}$ \\ 3515 Miskolc-Egyetemvaros, Hungary \\ ${ }^{2}$ Institute of Materials Science and Technology, University of Miskolc, H 3515 Miskolc- \\ Egyetemvaros, Hungary \\ accseh88david@gmail.com, ${ }^{b}$ femvali@uni-miskolc.hu, cjanos.lukacs@uni-miskolc.hu \\ *Tel: +36-46-450-111/10-97
}

\section{Keywords: Fatigue, Residual Stress Relaxation, X-ray Diffraction}

\begin{abstract}
The advantages of applied compressive residual stress on fatigue properties of materials is a well-described topic, but not in all respects. Compressive macro residual stresses in the surface region with medium and high hardness increase the fatigue life and the fatigue limit compared to materials that are free from designed compressive residual stresses because of their increased resistance against crack initiation and propagation. For this aim various surface compressing methods such as burnishing, shot peening, rolling have been developed. The monitoring of residual stress variation during fatigue is important. All properties, which exert lifetime, should be analyzed. The residual stress state of machine elements can change during application, therefore it is necessary to describe how these changes are related to the operational parameters. The surface residual stress state evolution of hardened (quenched and tempered)-and shot peened-42CrMo 4 steel during fatigue tests was investigated nondestructively by X-ray diffraction. Four fatigue stress levels were applied. The residual stress state was recorded in shot peened state and monitored during the fatigue tests. The fatigue test was stopped after certain cycles until the specimens fractured. The stress state was measured after each fatigue test stops and the stress relaxation is given in the percentage of the initial stress state in function of cycle number.
\end{abstract}

\section{Introduction}

Shot peening is a widely used surface compressing method to create compressive residual stress in machined elements $[1,2]$. The compressive residual stress state has a beneficial effect on the fatigue durability of metals, especially on fatigue strength $[3,4,5]$. For the assessment of the influence of residual stresses on fatigue behavior, the stability of the residual stress state is very important. During fatigue, the macro and micro residual stress states interact with the cyclic loading stresses and the work hardening and softening processes. For example the surface compressive residual stress improves the fatigue resistance properties of all materials.

The stability of the surface compressive residual stress during low and high cycle fatigue in annealed micro-alloyed, medium carbon, perlitic and austenitic steels has been already investigated $[6,-9]$. The authors have shown that the residual stress relaxation is not monotonic in these alloys. However, in general, machine elements, which are tipically exposed to high cycle fatigue loads; (gears, shafts) are mainly made of high strength hardened steels, therefore it is worth to investigate the stability of residual stress in such material. The stability of surcafe compressive residual stress on hardened, shot peened CM45MV specimens during fatigue was investigated in one of our eralier project [10]. Residual stress relaxation was not observable in that steel, because of the effect of microstructure defects and specimen geometry. In this paper, 
our aim was to analyze the variation of compressive residual stress state in shot peened hardened $42 \mathrm{CrMo} 4$ steel specimens during fatigue load. This is a widely used steel in the vehicle industry especially in the case of surface compressed machined elements. These measurements are based on our earlier project. Since then, the specimen geometry was improved and the material selection has changed.

Materials

The specimens were made of EN:42CrMo4 type steel. The chemical composition is given in Table 1 .

Table 1. Chemical composition of the examined steel

\begin{tabular}{|c|c|c|c|c|c|}
\hline \multicolumn{4}{|c|}{ Composition wt.\% } \\
\hline $\mathrm{C}$ & $\mathrm{Si}$ & $\mathrm{Mn}$ & $\mathrm{Cr}$ & $\mathrm{Mo}$ & $\mathrm{Ni}, \mathrm{V}, \mathrm{W}$, Co others \\
\hline 0.41 & 0.3 & 0.7 & 1.1 & 0.2 & - \\
\hline
\end{tabular}

Fatigue specimens were cut from a hot rolled bar with $20 \mathrm{~mm}$ diameter (Fig.1). The yield strength $(1200 \mathrm{MPa})$ and tensile strength $(1250 \mathrm{MPa})$ were measured by three parallel tensile tests on hardened test specimens made of the same piece of bar.

The faults of the heat treatments could strongly influence the residual stress state $[11,12,13$,$] .$ Our specimen geometry (long, thin) is especially sensitive on distortions, so the heat treatment was carried out with care. The specimens were immersed in oil by hand, used a pliers.

The specimens were induction hardened and oil quenched. To measure the temperature of the specimens and to control the inducer, $\mathrm{Ni}-\mathrm{NiCr}$ thermocouple was soldered to the surface. First, the specimens were rapidly heated to $1000^{\circ} \mathrm{C}$ during a few seconds then the temperature was held for 2 seconds When the sample reached $850^{\circ} \mathrm{C}$, the thermocouple was cut from the specimens and the specimens were immersed in quenching oil media, During the immersion the longitudinal axis was perpendicular to the surface of the media. The tempering was carried out at $600^{\circ} \mathrm{C}$ in an inductive furnace for half an hour, and specimens were subsequently cooled in air. The Fig. 2 shows the homogeneous martensitic microstructure of the cross section of the quenched and tempered sample. The HV10 (subscript) hardness data on the cross section $(332,337,339,361,341,333)$ confirms that the quenching was successful.

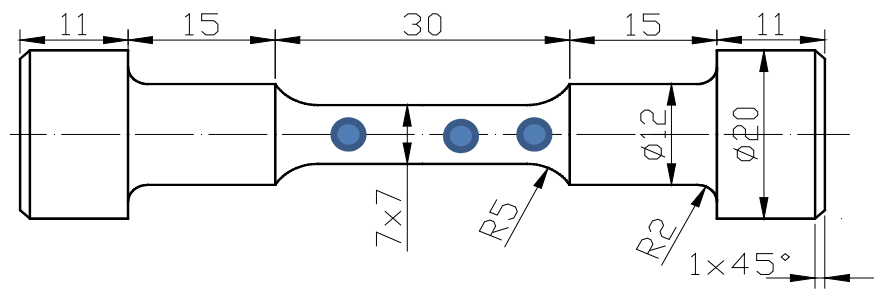

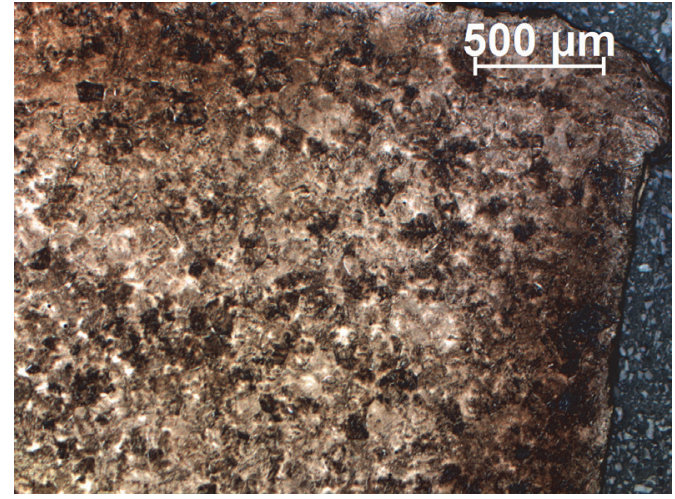

Figure 2. Light microscopy image of the hardened sample, cross section
Figure1. Size of the shot peened specimens

The monitored areas of the surface is indicated with blue spheres

The next step was the shot peening. It was performed in the Rába Automotive Holding Plc. The specimens were treated together with Rába manufactured shafts in the same time. The parameters of the shot peening were given by the requirements of the shaft. This means that the parameters of the applied peening method were industrial parameters. The shot peening was carried out in a WMKD 3 
type shot peening equipment (Fig.3). The peening time was 9 minutes. Two Almen $\mathrm{C}$ strips were fixed on the sample holders to control the peening. The values of the Almen $\mathrm{C}$ probes were 0.26 and 0.24 . The used peening balls were made of $1.8 \mathrm{~mm}$ diameter steel wire $(430 \mathrm{HV}$ ), cut in $1.8 \mathrm{~mm}$ length pieces and conditioned for 4 hours. The minimal peening coverage was $150 \%$. The average speed of the balls, which left the peening wheels was $55 \mathrm{~m} / \mathrm{s}$. As an average $117 \mathrm{~J} / \mathrm{mm}^{2}$ energy was imparted with the surface. The performance of the peening wheels was $252 \mathrm{~kg} / \mathrm{min}$.

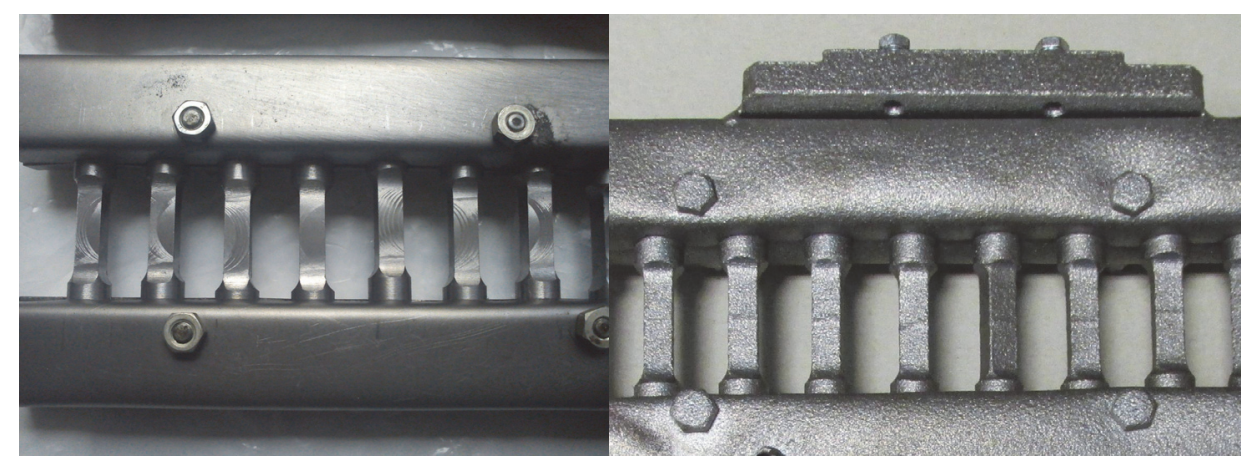

Figure 3. Right: the specimens in the sockets before shot peening, Left: specimens after shot peening, with the Almen Cholder. The heads of the specimens were shadowed during the peening.

\section{Experiments}

The residual stress was measured non-destructively by a Stresstech Xstress 3000 G3R X-ray diffractometer, resident at the Institute of Physical Metallurgy, Metalforming and Nanotechnology at the University of Miskolc. Our surface results regard to residual stress values from approximatelly 10 $\mu m$ depth of the surface layer. All of our residual stress values refer to this layer. The stress was calculated from the shift of the $\{211\}$ reflection of ferrite according to the $\sin ^{2} \psi$ method using Young's modulus (E) of $210000 \mathrm{MPa}$ and Poisson's ratio of 0.29 . Reflections were obtained in $\psi$ geometry from 3 tilting positions in the $-45^{\circ} / 45^{\circ}$ range according to Fig. 4 . The spot size was $3 \mathrm{~mm}$ in diameter. The stress was measured with less error (scatter) than $\pm 10 \mathrm{MPa}$ in every point [10]. Fig 4 shows an example of the measured results in one point of sample No.1. The shear stress was under the $7 \mathrm{MPa}$ value in every cases.

All four sides of the specimens were monitored. The axial residual stress state was recorded at 3 spots with $3 \mathrm{~mm}$ spot size areas, on each side of each specimen in the initial shot peened state and during the fatigue loads. The same areas were investigated in each step of the monitoring. The fatigue schedule is given in Table 2. The represented stress value is always an average of twelve data after each step. First, the residual stress field of the shot peened state was recorded, (Table 2- in.RS) then, as the specimens were fatigued and stopped (as it is given is Table 2.) the residual stress state was measured again and again until the fracture of the specimen was reached. The first six specimens were fatigued until fracture without stop. In the possession of the results of the preliminary fatigued six specimens, the expected lifetime was determined. The cycle number at the first stop was defined based on the result of the first six specimens.

The fatigue load was tensile-compressive, the stress ratio $\left(R_{\sigma}\right)$ was $-1\left(R_{\sigma}=\sigma_{\min } / \sigma_{\max } ; \sigma_{\max }=350\right.$; 400; 450; $500 \mathrm{MPa}$ ); so the absolute values of the tensile and compressive stresses were equal. The cyclic load was implemented by an MTS type universal electro-hydraulic testing machine of the Institute of Materials Science and Technology at the University of Miskolc. 

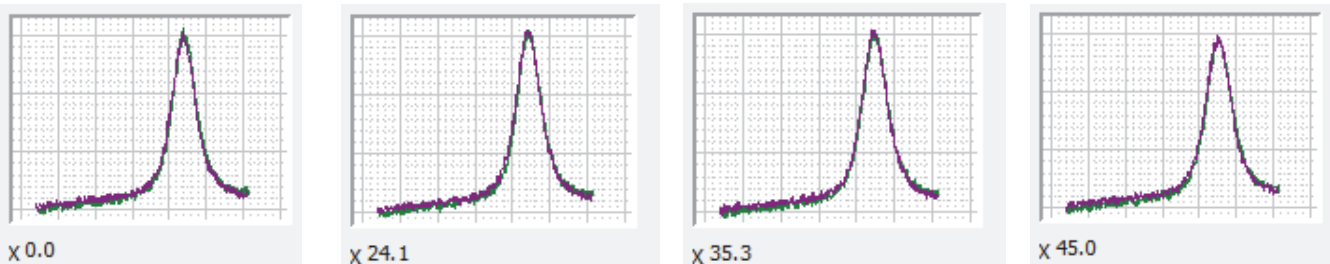

$\times 24.1$

$\times 35.3$

$x 45.0$
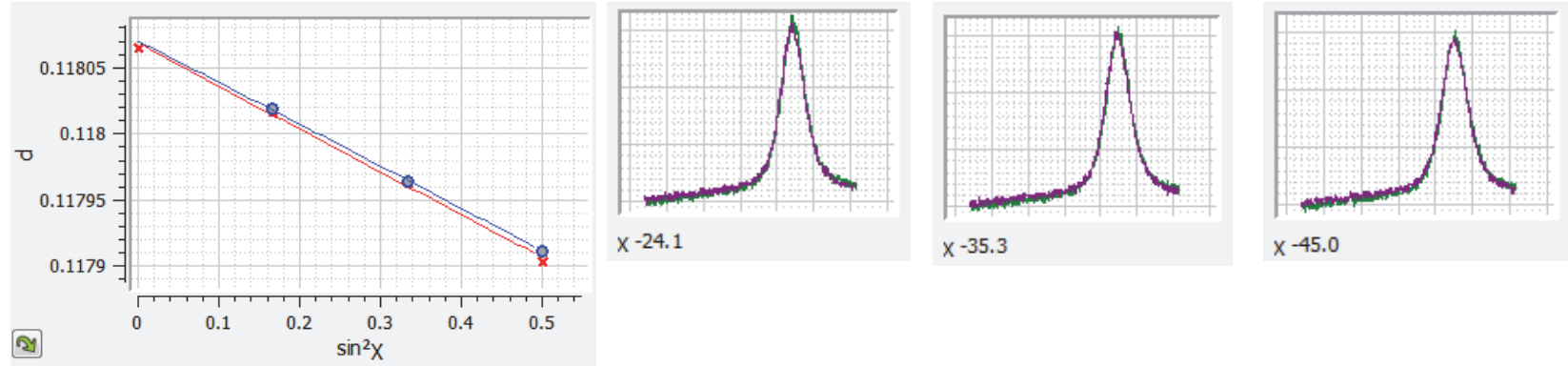

$x-35.3$

$x-45.0$

Figure 4.The result of one measured data of sample No. $1, \chi$ is the tilting angle $\left[{ }^{\circ}\right], d$ lattice distance [nm]

Table 2. The schedule of the fatigue tests

\begin{tabular}{|c|c|c|c|c|c|c|c|c|c|c|c|}
\hline No. & $\begin{array}{c}\text { size } \\
{[\mathrm{mm}]}\end{array}$ & $\begin{array}{l}\text { in. } \\
\text { R.S } \\
{[\mathrm{MPa}]}\end{array}$ & $\begin{array}{c}\sigma \\
{[\mathrm{MPa}]}\end{array}$ & $\begin{array}{c}\text { cycle } \\
\text { numbers } \\
\text { in the first } \\
\text { step }\end{array}$ & $\begin{array}{l}\text { additional } \\
\text { cycle } \\
\text { numbers }\end{array}$ & No. & $\begin{array}{c}\text { size } \\
{[\mathrm{mm}]}\end{array}$ & $\begin{array}{c}\text { in. } \\
\text { R.S } \\
{[\mathrm{MPa}]}\end{array}$ & $\begin{array}{c}\sigma \\
{[\mathrm{MPa}]}\end{array}$ & $\begin{array}{l}\text { cycle } \\
\text { numbers } \\
\text { in the } \\
\text { first step }\end{array}$ & $\begin{array}{l}\text { additional } \\
\text { cycle } \\
\text { numbers }\end{array}$ \\
\hline 1 & $7 \times 7$ & -450 & 510 & \multirow{6}{*}{\multicolumn{2}{|c|}{$\begin{array}{l}\text { Load to fracture } \\
\text { without stop, } \\
\text { (preliminary } \\
\text { atigued specimens } \\
\text { for life time } \\
\text { estimations) }\end{array}$}} & 10 & $5 \times 5$ & -407 & 500 & 20000 & 12500 \\
\hline 2 & $7 \times 7$ & -391 & 450 & & & 11 & $5 \times 5$ & -360 & 450 & 30000 & 20000 \\
\hline 3 & $7 \times 7$ & -279 & 450 & & & 12 & $5 \times 5$ & -348 & 400 & 45000 & 30000 \\
\hline 4 & $7 \times 7$ & -373 & 400 & & & 13 & $5 \times 5$ & -332 & 350 & 70000 & 45000 \\
\hline 5 & $7 \times 7$ & -264 & 400 & & & 16 & $7 \times 7$ & -225 & 500 & 45000 & 12500 \\
\hline 6 & $7 \times 7$ & -356 & 400 & & & 17 & $7 \times 7$ & -254 & 450 & 70000 & 20000 \\
\hline 7 & $7 \times 7$ & -244 & 500 & 20000 & 12500 & 18 & $7 \times 7$ & -351 & 400 & 11000 & 30000 \\
\hline 8 & $7 \times 7$ & -392 & 450 & 30000 & 00 & 19 & $7 \times 7$ & -244 & 450 & 50000 & 20000 \\
\hline 9 & $7 \times 7$ & -282 & 400 & 45000 & 30000 & 20 & $7 \times 7$ & -259 & 350 & 70000 & 45000 \\
\hline $\mathrm{H}$ & $7 \times 7$ & 12 & 350 & 70000 & 45000 & & & & & & \\
\hline
\end{tabular}

Results

The initial average residual stress values of the specimens showed a great deviation (Table 2.) The average values of the different samples were located between 225-450 MPa interval, this scattering is caused by the rough shot peening. The surface compressive residual stress relaxation of the shot peened specimens was measured at four applied stress amplitudes (500, 450, 400, $250 \mathrm{MPa})$. One specimen was fatigued in as-hardened state, so it was given no shot peening treatment. This specimen is indicated with a " $\mathrm{H}$ " letter and was fatigued at the lowest stress amplitude. It survived around 80000 cycles.

Fig. 5. shows the residual stress relaxation at different stress levels during fatigue loads. (Specimens 14 and 15 were notched then, investigated in another way and not presented here.) Each illustrated point is an average value of twelve performed measurements on the four sides of one specimen. Lines in group $450 \mathrm{MPa}$ and $400 \mathrm{MPa}$ show large scattering. The larger residual stress relaxation is not related to the larger absolute value of initial average residual stress. This scattering is acceptable in such kind of measurements. 
In order to monitor the stress variation, the residual stress values measured during the fatigue tests, are presented as percentage values of the initial stress states. This unintentional scattering of the average surface residual stress measured in our specimens let us to investigate the role of it during the inspected phenomenon.

The significance of the fatigue stress amplitude is multiple: the higher stress level results shorter lifetime, and higher extent of residual stress relaxation.

To test the sample size effect on the residual stress relaxation during the fatigue load, the thickness of six specimens (No. 10-15) was decreased $(5 \times 5 \mathrm{~mm})$ and shot peened again with the same peening parameters. No systematic effect is connected to the sample size. The stress relaxation rate shows an increased level by increasing the fatigue stress amplitude. It is evident that the rate of the stress relaxation is very fast in the first thousands of the cycles.
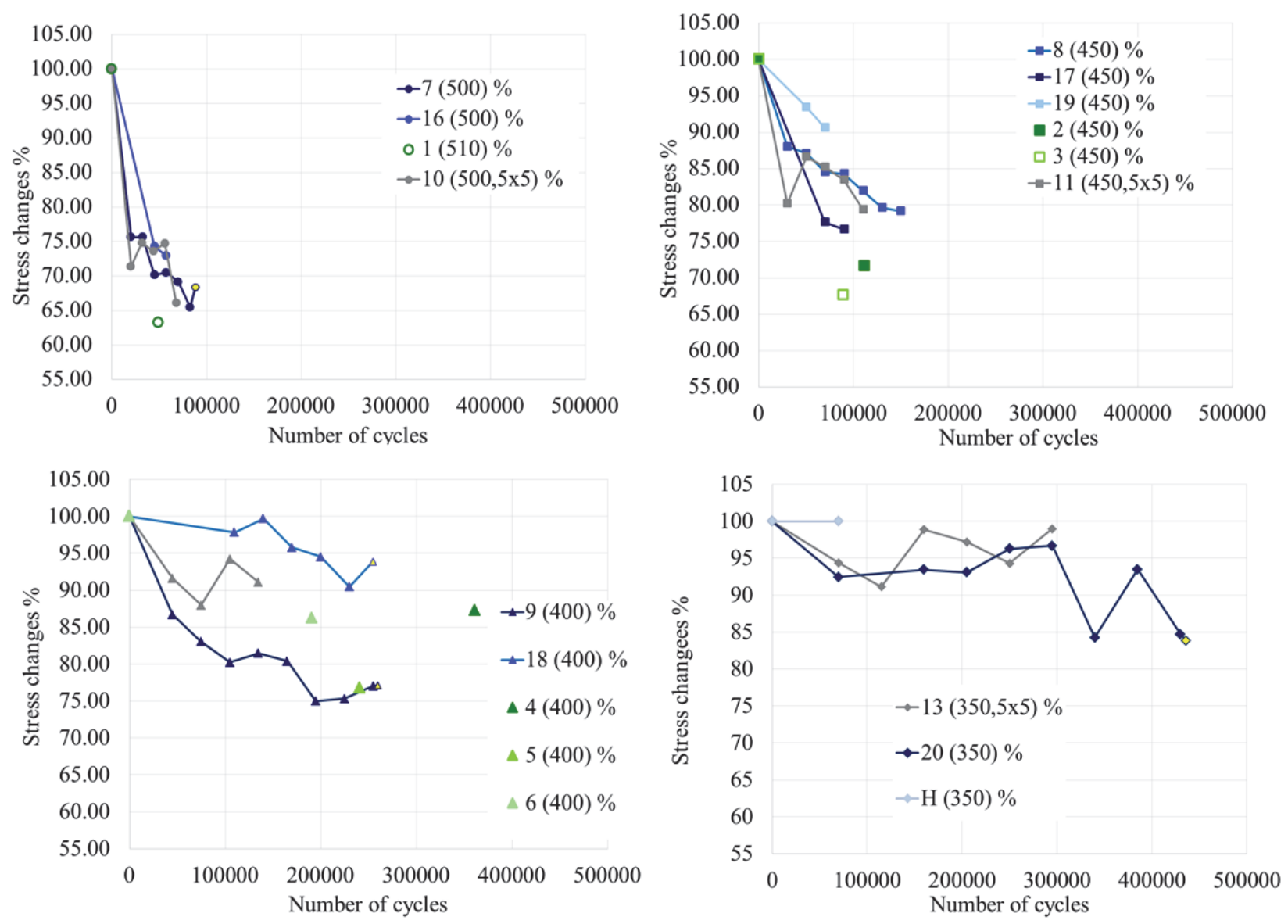

Figure 5. The residual stress relaxation at single stress levels during fatigue loads

\section{Summary}

Stress relaxation of quenched and tempered $42 \mathrm{CrMo} 4$ steel was investigated during fatigue test. Fatigue specimens were cut and shot peened with industrial parameters. The surface compressing residual stress stability was investigated using different fatigue stress levels. Non-destructive residual stress measurements were carried by X-ray diffraction method. The fatigue load was stopped several times (3-10 stops depend on specimens) and the residual stress state is monitored in each steps. The stress relaxation is given in the percentage of the initial stress state in function of cycle number.

No sample size effect in the rate of relaxation was observable. The beneficial impact of shot peening appears in small number of cycles until the fracture of the as-hardened sample. The rate 
of the stress relaxation is faster in the first thousands of the cycles. The higher fatigue stress amplitude indicates larger extent of residual stress relaxation. The absolute value of the initial residual stress state does not have systematic effect during the relaxation. The higher relaxation has no correlation with the value of the initial residual stress.

Our concept regards to high strength steel specimens. None of the applied fatigue stress levels reached the half of the yield strength. Our results are related to others (Dalaei and Kim) with differences in the material selection and in the quotient of the applied fatigue stress levels and the yield strength. Our results confirm the permission of the expansibility of the declared observations in case of steel, independently by material quality and heat treatment state.

\section{Acknowledgement}

This work has been carried out as part of the TÁMOP-4.2.1.B-10/2/KONV-2010-0001 project within the framework of the New Hungarian Development Plan. The realization of this project is supported by the European Union, co-financed by the European Social Fund.

\section{References}

[1] J. Davis, Surface hardening of steels, USA: ASM International, 2002.

[2] S. Timoshenko, History of strength of materials, Dover: Dover Publications, 1983.

[3] ASM International, Handbook of Residual Stress and Deformation of Steel, USA: 2002.

[4] R. I. Stephens, A. Fatemi, R. R. Stephens és H. O. Fuchs, Metal fatigue in Engineering 2nd Edition, USA: John Wiley \& Sons, 2001.

[5] E. Macherauch és V. Hauk, Residual stress in Scinence Technology Vol 2, Németország: I.R. Publications, 1987.

[6] K. Dalaeia, B. Karlssona és L.-E. Svenssona, ,Stability of shot peening induced residual stresses and their influence on fatigue lifetime," Mat. Science and Engineering A, pp. 1008-1015, 2010.

[7] J.-C. Kim, S.-K. Cheong és H. Nog, ,Residual stress relaxation and low- and high-cycle fatigue behavior of shot-peened medium-carbon steel," International Journal of Fatigue, pp. 114-122, 2013. http://dx.doi.org/10.1016/j.ijfatigue.2013.07.001

[8] J.-C. Kim, S.-K. Cheong és H. Nog, „Proposed fatigue damage measurement parameter for shotpeened carbon steel..." International Journal of Fatigue, pp. 97-106, 2014.

[9] I. Nikitin és M. Besel, „Correlation between residual stress and plastic strain amplitude during low cycle fatigue of mechanically surface treated austenitic stainless steel AISI 304 and ferriticpearlitic steel SAE 1045," Materials Science and Engineering A, pp. 297-303, 2008.

[10] D. Cseh, V. Mertinger és J. Lukács, „Residual Stress Evolution During Fatigue Test of a Shoot Peened Steel Sample," Materials Science Forum , pp. Vol. 752 95-104, 2013.

[11] ASM International, Cast Irons ASM Specialty Handbbok, USA: ASM International, 1996.

[12] ASM International, Heat treating ASM Handbook Vol. 4, USA: ASM International, 1991.

[13] R. Haimbaugh, Induction Heat Treating, USA: ASM International, 2001 